supported. The child protection system does not cause the deaths-none of the children died as a result of abuse or violence by parents or foster parents. However, the system fails to protect adolescents from self endangering behaviour both within the system and during adaptation to independent living. The results indicate the need for continuing attention to be paid to the transition period from foster care to independence.

We thank the Ministry of Social Welfare and Health, the National Research and Development Centre for Welfare and Health, Statistics Finland, and the Data Protection Authority for giving permission to link the registers.

Contributors: MK designed and coordinated the study and wrote the paper, THP analysed the data and wrote the paper.JM did the data linkage and produced the data. JS interpreted the data, supervised the study, wrote the paper, and is the guarantor. Funding: Academy of Finland, Research Council for Culture and Society.

Competing interests: None declared.

1 Östberg V. Social class differences in child mortality in Sweden 1981-1986. J Epidemiol Community Health 1992;46:480-4.

2 Thompson AH, Newman SC. Mortality in a child welfare population: implications for policy. Child Welfare 1995;74:843-55.

3 Vinnerljung B. Mortalitet bland fosterbarn som placerats före tonåren [Mortality among children in foster care placed before teenage]. Socialvetenskaplig Tidskrift 1995;1:60-72.

4 Pensola T, Valkonen T. Mortality differences by parental social class from childhood to adulthood. J Epidemiol Community Health 2000;54:525-9.

5 Rosenfeld AA, Pilowsky DJ, Fine P, Thorpe M, Fein E, Simms MD, et al. Foster care: an update. J Am Acad Child Adolesc Psychiatry 1997;36:448-57. (Accepted 14 February 2001)

\title{
Social environments and health: cross sectional national survey
}

Andrew McCulloch

Institute for

Economic and

Social Research,

University of Essex,

Colchester

CO4 3SQ

Andrew McCulloch senior research officer

amccul@essex.ac.uk

BMJ 2001;323:208-9
Researchers are increasingly interested in studying the effects of the social environment on health. ${ }^{1}$ The concept of social capital has been put forward as one explanation for why some communities work better than others, with benefits for the whole of the local population. ${ }^{2}$ Social capital is applied to those features of a community that promote cohesion and a sense of belonging and that enable its members to cooperate. Similarly, criminologists have argued that the level of social organisation in a neighbourhood, or the degree to which residents are able to realise common goals and exercise social control, links the social composition of a neighbourhood and rates of deviant behaviour. ${ }^{3}$ We investigated how individual's reports of social capital and social disorganisation are associated with health outcomes among men and women aged 16 to 54 from a representative cross section of British households.

\section{Methods and results}

The British Household Panel Study is an annual survey of a representative cross section of British households. ${ }^{4}$ The first wave of interviews took place between

Table 1 Effect of social capital and social disorganisation on risk of poor health

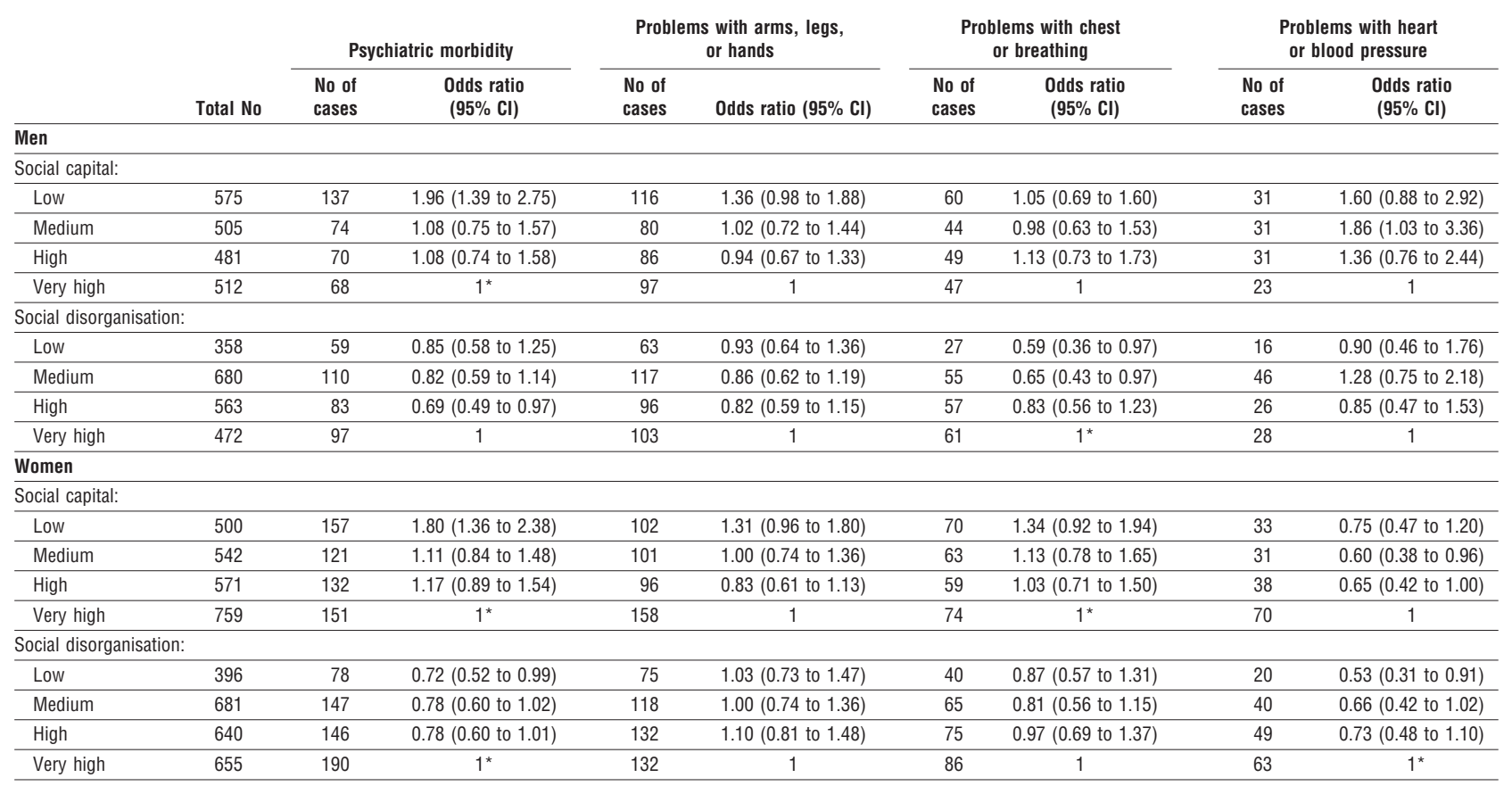

*Trend test: $\mathrm{P}<0.05$.

Models were additionally adjusted for age, education, social support, deprivation, low income, marital status, smoking, and economic activity. 
September and December 1991. Our analysis is based on surveys in 1998 and 1999. Respondents were asked eight questions about their neighbourhood. We summed responses and divided them into low, medium, high, and very high levels of social capital. We also summed responses to eight questions about various community problems and divided them into low, medium, high, and very high levels of social disorganisation. We assessed psychiatric morbidity using the 12 item general health questionnaire. ${ }^{5}$ People scoring 3 or more were classified as cases. We also analysed reported physical health problems related to arms, legs, or hands (including arthritis); chest or breathing; and heart or blood pressure.

We used logistic regression analysis to examine the relative influence of social capital and perceived disorganisation on health after controlling for other factors. Separate models were computed for men and women.

The table shows the number of men and women with poor health outcomes for each level of social capital and social disorganisation. Men in the lowest category of social capital were more likely to report psychiatric morbidity than men in the highest category (odds ratio 1.96, 95\% confidence interval 1.39 to 2.75). Men in the lowest quartile of social disorganisation were less likely to report chest or breathing problems than men in the highest category $(0.59,0.36$ to 0.97$)$. Psychiatric morbidity was more common among women in the lowest categories of social capital compared with women in the highest category (1.80, 1.36 to 2.38). Women in the lowest category of social disorganisation had lower rates of psychiatric $(0.72$, 0.52 to 0.99$)$ and heart or blood pressure problems $(0.52,0.21$ to 0.91$)$ than those in the highest category. These associations were independent of individual age, education, smoking, material deprivation, marital status, social support, and economic activity.

\section{Comment}

We found that people in the lowest categories of social capital had increased risk of psychiatric morbidity and that those in the lowest categories of social disorganisation had lower rates of some health problems. This research adds to the evidence on the influence of social environments on health.

Social relationships lead to the development of norms of trust and reciprocity that have spillover effects within neighbourhoods as a whole. Resources are potentially available to everyone within the neighbourhood, not just those who invest in maintaining relationships. Likewise, conditions that lead to social disorganisation are not associated just with individual victims but are detrimental to the health of all members of society. Understanding the ways in which the social environment affects health is important to improve our knowledge of how health inequalities arise and how they can potentially be reduced.

Questionnaires and further details about the British Household Panel Study are available at www.iser.essex.ac.uk/bhps

Contributors: AMcC is the sole contributor to this paper.

Funding: ESRC Grant L130251010.

Competing interests: None declared.

1 Marmot M. Improvement of social environment to improve health. Lan cet 1998;351:57-60.

2 Campbell C. Social capital and health. London: Health Education Authority, 1999.

3 Sampson RJ, Groves WB. Community structure and crime: testing social disorganization theory. Am J Sociol 1989;94:774-802.

4 Taylor MF. British household panel survey user manual volume A: introduction technical report and appendices. Colchester: University of Essex, 1999.

5 Goldberg DP. The detection of psychiatric illness by questionnaire. London: Oxford University Press, 1972.

(Accepted 4 July 2001)

\section{Un homme différent}

I had been the family's doctor for 12 years. They lived in a small, remote village. One September the father-a tall, physically fit schoolmaster-came to my surgery. "It's stupid," he said, "I just got back from holiday but I feel tired. I was with some colleagues last Monday and I had trouble finding and pronouncing some words during a conversation." The results of a clinical examination and blood test were normal.

A few weeks later I was called to his home. His family was very worried. He had been having headaches and was sleeping a lot. But when he was sitting in front of me he made only a few complaints.

I rang the lab for the results of a new blood test. The test showed recent cytomegalovirus infection and infectious mononucleosis. "I have an explanation," I said, coming back from the phone. He seemed relieved; two tears slid down his cheeks.

Then the situation worsened: he lost his balance. I could not wait for him to be seen at his appointment for cerebral computed tomography. I admitted him to hospital. An emergency scan showed a tumour with oedema. He was transferred to a neurosurgery centre where he underwent surgery.

Ten days later, on a Friday morning, he and his wife came to my surgery for the results. I had to confirm a bad one: he had a malignant glioma. After answering his few precise questions, I noticed that he seemed to be in the best shape of any of us in the room.
For nine months he conscientiously followed the timetable of radiotherapy and chemotherapy. He kept track of his appointments in a notebook. He was excluded from a gene therapy trial.

I saw him every month for his treatment. I found that I needed the support of some colleagues in Le Mans: a network of general practitioners and my local Balint group, where the conscious and unconscious relationships between doctors and their patients are explored.

In July, after I returned from spending a few days in England, I visited him. He could no longer speak. He offered just a last, enigmatic smile. He died at the end of the summer holidays. I was with him at his home, as he and his family had wished. It had been difficult: we were the same age.

Some years later the dignity that this man and his family had during his illness, and the way that he had spared those closest to him, are still in my mind. The last words of Jean-Paul Sartre's novel Les Mots are: "Un homme fait de tous les hommes et qui les vaut tous, et que vaut n'importe qui [A whole man composed of all men and as good as all of them and no better than any]." When I think of this patient, I cannot agree with Sartre's view.

Jean-Yves Panici general practitioner, Brette les Pins, Sarthe, France 